\title{
Phytochemical Investigation of Calophyllum inophyllum Linn.
}

Praveena Ch*, Swaroopa Rani S and Veeresham C

Department of Medicinal Plant Biotechnology Laboratory, University College of Pharmaceutical Sciences, Kakatiya University, Warangal, AP-506009, India

\begin{abstract}
Calophyllum inophyllum Linn. is an economically and medicinally important species of genus Calophyllum, family Guttiferae. The plant is known for its abundant traditional medicinal value, as well as for its pharmacological activities, such as antiviral, cytotoxic, anti-platelet aggregation, etc. Phytochemical literature investigation of the plant revealed the presence of various compounds, such as coumarins, xanthones, triterpenes and steroids. However, steroidal glycosides are not reported from this plant. In search of new chemical compounds, phytochemical investigation of methanolic extract of leaves was carried out. After repeated column chromatography using Hexane and Hexane:Ethyl acetate mixtures of different proportions as eluents, resulted in isolation of three compounds suspected to be steroidal compounds. The homogeneity of isolated compounds was established by TLC and HPLC, as there was no interference of spot or peak in chromatograms. For detailed structure elucidation, UV, IR, one dimensional H1NMR, C13 NMR and MS spectras were recorded for structure elucidation.
\end{abstract}

Keywords: Calophyllum inophyllum; Column chromatography; Spectra

\section{Introduction}

Calophyllum inophyllum Linn. is an economically and medicinally important plant belonging to the family Guttiferae (Clusiaceae). The genus comprises of about 180-200 species widespread in humid tropics. Although a handful species have been identified in the new world, the genus is primarily found in the Indo-Pacific region, particularly Malaysia [1].

Different parts of the plant, such as leaves, bark and seeds possess medicinal value, and can be used as astringent, antiseptic, diuretic, purgative and expectorant. Oil from the nuts traditionally has been used as a medicine and as a cosmetic [2]. C. inophyllum is one of the most abundant plant of this genus is reported to contain diverse compounds like coumarins, xanthones, flavonoids, steroids and triterpenoids [311]. Few of these compounds are reported to have bioactivities, such as anti-HIV, anti-cancer, anticoagulant, anti-inflammatory, antiplatelet aggregation activity [12-17]. Though the plant has been reported to contain diverse chemical compounds, still in search of new compounds from this plant phytochemical investigation was carried out and three compounds were isolated from leaves. Homogeneity of the compounds was confirmed by TLC and HPLC techniques. UV, IR, one dimensional NMR and Mass spectral data were recorded, in order to elucidate the structure of these compounds.

\section{Experimental Procedure}

\section{Collection of plant material}

The leaves of C. inophyllum were collected in the month of September in Hanamkonda, Warangal, Andhra Pradesh, India. A voucher specimen of the plant is being maintained in the herbarium of University College of Pharmaceutical Sciences, Kakatiya University, Warangal.

\section{Preparation of methanolic extract of the leaves}

The leaves collected were thoroughly washed and made free from the adherent foreign material and air dried. Then, they were coarsely powdered. $750 \mathrm{gm}$ of powder was macerated with methanol in a round bottom flask for 7 days. The contents of flask were stirred intermittently to ensure the efficiency of the extraction. After 7 days, contents of the flask were filtered and the filtrate was concentrated under reduced pressure. The obtained extract was kept in desiccators to remove moisture and stored properly until used. The methanolic extract of leaves was subjected to various chemical tests to know the nature of the compounds present. TLC examination of the methanolic extract of leaves in different solvent systems, both on normal and reverse phases was carried out.

\section{Column chromatography of methanolic extract of leaves}

Methanolic extract was subjected to open column chromatography on silica gel (230-400 mesh size), as the stationary phase. The column was eluted with Hexane, Hexane: Ethyl acetate in gradient manner.

\section{Thin Layer Chromatography}

TLC of fractions was done by using standard procedure for detection of phytochemicals, monitoring the progress of column chromatography, and for testing the homogeneity of the isolates. Precoated, normal phase and reverse phase (C18) silica gel 60 F254 plates (Merck, Germany) were used as the stationary phase.

Detection of phytochemicals on the TLC plates after development was done by first observing under normal daylight, then under UVlight using a Ultra-Violet fluorescence analysis cabinet (Macro scientific works, Delhi), and then sprayed with vanillin-sulphuric acid (VS) reagent. VS reagent consists of: Solution I: 5\% Methanolic solution of sulphuric acid. Solution II: $1 \%$ Methanolic solution of vanillin. The plates were first sprayed vigorously with solution-I so as to wet it, followed by solution-II and then heated for $3-4 \mathrm{~min}$ at $110^{\circ} \mathrm{C}$ under observation. Steroids/triterpenoids and their glycosides give blue, blue-violet or pink spots, and the yellow colour of flavonoids and their glycosides gets intensified [18].

\section{High Performance Liquid Chromatography}

Homogeneity of the pooled fractions was further confirmed by

*Corresponding author: Praveena Ch, Department of Medicinal Plant Biotechnology Laboratory, University College of Pharmaceutical Sciences, Kakatiya University, Warangal, AP-506009, India, Tel: 919441672322; E-mail: praveenamr18@yahoo.co.in

Received September 16, 2013; Accepted October 14, 2013; Published October 20, 2013

Citation: Praveena Ch, Swaroopa Rani S, Veeresham C (2013) Phytochemical Investigation of Calophyllum inophyllum Linn. Nat Prod Chem Res 1: 119 doi: 10.4172/ 2329-6836.1000119

Copyright: (c) 2013 Praveena Ch, et al. This is an open-access article distributed under the terms of the Creative Commons Attribution License, which permits unrestricted use, distribution, and reproduction in any medium, provided the original author and source are credited. 
performing HPLC analysis. The fractions which were found to give single spot in TLC analysis were pooled and subjected to HPLC analysis. HPLC system consisted of solvent delivary module LC-8A, Shimadzu model connected to SPD-10Avp, PDA detector. Analytical column was Reverse Phase C-18 column ( $250 \mathrm{~mm} \times 4.6 \mathrm{~mm}, 5 \mu$; GraceSmart). The mobile phase was methanol: water (90:10) degassed using bath sonicator. The chromatography was performed at a flow rate of $1 \mathrm{ml} /$ min at room temperature.

\section{Spectral data}

The UV spectrum of the isolates was recorded in methanol, using Elico SL-164 double beam UV-Visible spectrophotometer. The IR spectrum of the isolates was recorded in KBr pellet, using Perkin-Elmer 281B IR spectrophotometer, model spectrum BX series. NMR spectra were recorded Bruker spectrometer in $\mathrm{MeOD}$ solution at $400 \mathrm{MHz}$. Mass spectra was recorded in LC/MS 1100 series.

\section{Results}

Preliminary phytochemical investigation of methanolic extract of leaves by tests tube reactions revealed that it contains flavonoidal glycosides, steroidal glycosides.

\section{Characterization of fractions}

Maceration with methanol gave $30 \mathrm{gm}$ of extract after complete evaporation of solvent. The obtained extract was subjected to column chromatography. Total of 198 fractions of each $\sim 40 \mathrm{ml}$ were collected by column chromatography of methanolic extract and fractions showing similar TLC pattern profile were pooled together. The fractions 118-126 were showing a single spot in normal phase TLC analysis with same Rf value. So they were pooled and evaporated to get a compound, which was given the code CI-1 (100 mg). TLC study of fractions 127-131 revealed that they also contain single compound and pooled together to evaporate, and to get a compound which was given the code CI-2 (75 mg).

TLC study of fractions 132-137 have shown two light green spots and one violet spot, and these three components were present in good concentration. Hence, these fractions were combined and given the code Fr. 3 (580 mg). This fraction, Fr. 3, as it contains 3 compounds was further subjected to column chromatography on normal silica gel (230400 mesh) using Hexane: Ethyl acetate 70: 30 as eluent in order to isolate pure compounds. Total of 141 fractions of $5 \mathrm{ml}$ each were collected and TLC of each fraction was carried out to know the homogeneity of fractions. The fractions 51-58 were showing the same spot on TLC. Hence, they were pooled together and evaporated to get a material, and was given the code CI-3 (29 mg). In other fractions, several spots were observed, indicating the presence of mixture of compounds. Hence, they were not further evaluated.

\section{Characterization of CI-1}

CI-1: Yellow crystalline material and gave positive LibermannBurchard test indicating that it is a steroid, and gave a purple colour ring in Molish test indicating that it is a glycoside. Single light green coloured spot on normal TLC was observed after running in Hexane: Ethylacetate(70: 30), with Rf value of 0.6. And further in HPLC analysis, gave single peak at $\lambda_{\max } 204 \mathrm{~nm}$ with Rt $4.6 \mathrm{~min}$, confirming its homogeneity (Figure 1).

UV spectrum: UV spectrum of CI-1 was recorded in methanol. It has shown two bands, band A with $\lambda_{\max }$ at $203 \mathrm{~nm}$ and band B with $\lambda_{\max }$ at $273 \mathrm{~nm}$. The peak at $273 \mathrm{~nm}$ indicates that CI-1 have chromophores and absorption in the UV region. This, in turn, indicates that there is a conjugation in the molecule.

IR ( cm$\left.^{-1}\right): 822(\mathrm{C}-\mathrm{H}), 1081$ (C-O-C), $1384(\mathrm{C}-\mathrm{O}), 1458$ (CH3), 1693(C=O), 2976(C-H), 3568(O-H).

${ }^{1} \mathrm{H}$ NMR (ppm) $\delta: 0.805(\mathrm{~s}), 0.898$ (s), 1.11 (d), 1.17 (d), 1.44 (d), $2.55(\mathrm{p}), 5.38(\mathrm{dd}), 6.3(\mathrm{~d}), 6.45(\mathrm{~d}), 7.25(\mathrm{~m})$

$\mathrm{C}_{13}$ NMR: Peaks at $\delta 129.96(\mathrm{~d}), \delta 129.35(\mathrm{~s}), \delta 128.15(\mathrm{~d}), 127.41(\mathrm{~s})$, 121.68(s), 116.47(d), 80.56(d), 79.34(d), 28.63(d), 28.22(s), 27.82(s), $19.84(\mathrm{~s}), 10.48(\mathrm{t})$.

Mass spectrum: The mass spectrum of CI- 1 had a molecular weight 420 , the base peakt 419.2((M-H)=419). Mass spectrum is depicted in Figure 2.

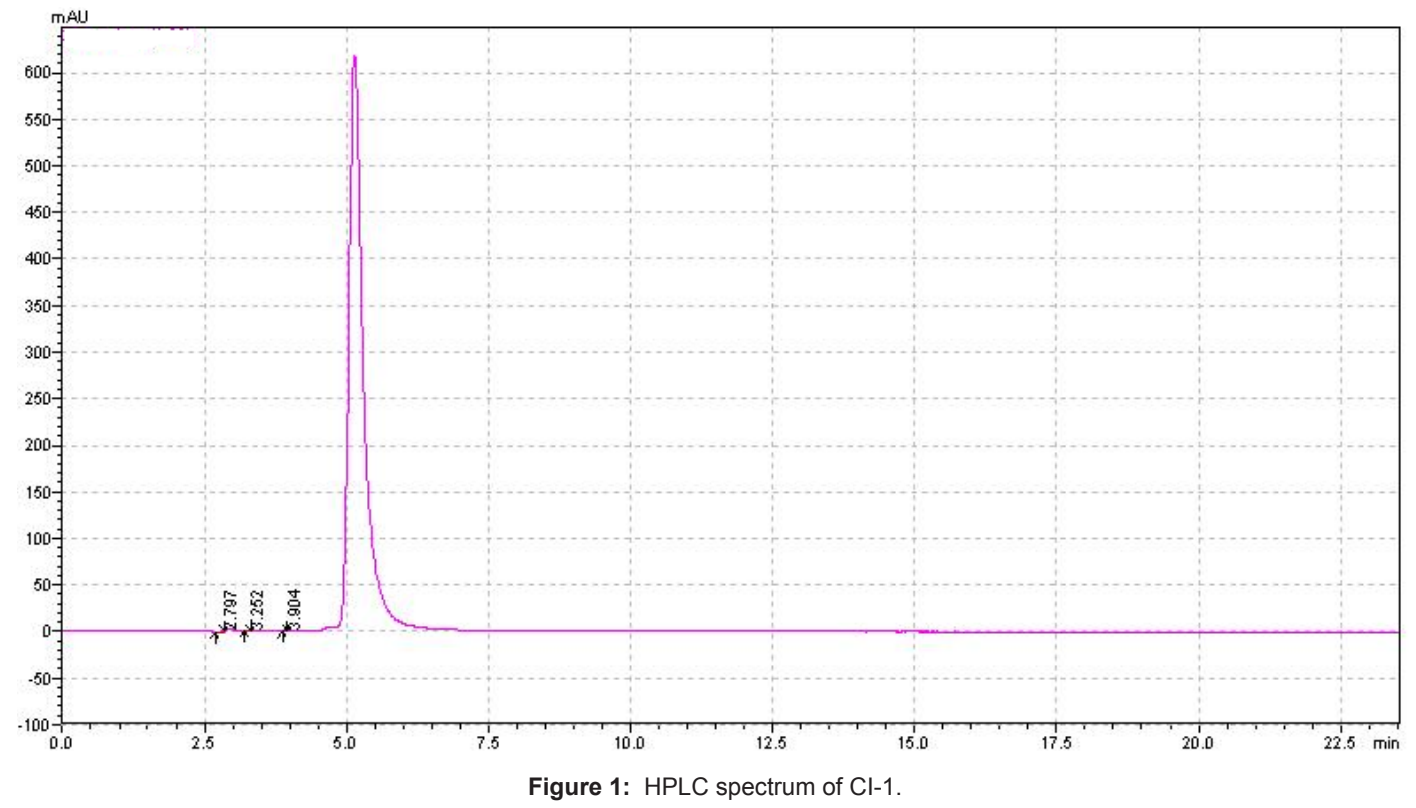


Citation: Praveena Ch, Swaroopa Rani S, Veeresham C (2013) Phytochemical Investigation of Calophyllum inophyllum Linn. Nat Prod Chem Res 1: 119 doi: 10.4172/ 2329-6836.1000119

Page 3 of 4

\section{Characterization of CI-2}

CI-2: Lemon yellow coloured powder gave red colour in LibermannBurchard test, indicating that it is a steroid/terpenoid. Compound CI-2 was found to be homogeneous when tested on normal phase TLC and reverse phase TLC. Further HPLC analysis also confirmed the homogeneity by giving a single peak at $\lambda_{\text {max }}$ at $203 \mathrm{~nm}$ with Rt $4.73 \mathrm{~min}$ (Figure 3)

UV spectrum: UV spectrum of CI-2 was recorded in methanol showed absorption band at $\lambda_{\max } 204 \mathrm{~nm}$. This is the characteristic feature of triterpenoid/steroid.

IR $\left(\mathbf{c m}^{-1}\right)$ : $3650(\mathrm{O}-\mathrm{H}), 2977(\mathrm{C}-\mathrm{H}), 1693(\mathrm{C}=\mathrm{O}), 1443(\mathrm{C}-\mathrm{H})$, 1342(C-O), 1196(C-O-C), 867(C-H).

${ }^{1} \mathrm{H}$ NMR (ppm) $\delta: 0.821(\mathrm{~s}), 0.88$ (s), 1.09 (q), 1.17(d), 1.133 (q), 2.53(m), $4.59(\mathrm{q}), 5.38(\mathrm{dd}), 6.31(\mathrm{~d}), 6.45(\mathrm{~d}), 7.26(\mathrm{~m})$.

$\mathrm{C}_{13}$ NMR: Peaks at $\delta$ 202.68(d), 169.12(d), 159.98 (s),157.73(d), 149.42(d), 142.15(d), 129.97(s), 129.37(s), 128.15(d), 127,45(s), 121.65(s), 116.44(s), 109.63(d), 102.72(d), 79.38(d), 78.02(s), 77.90(s), 28.65(d), 28.22(s), 27.93(s), 16.55(d), 9.69(d).

Mass spectrum: The mass spectrum of CI-2 had a molecular weight

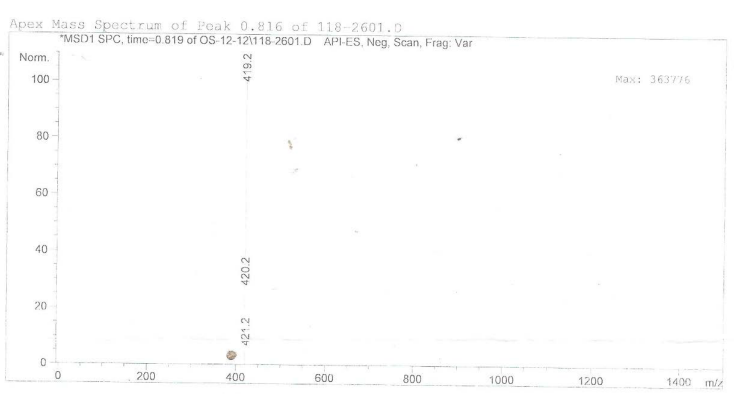

Figure 2: MS spectrum of $\mathrm{Cl}-1$

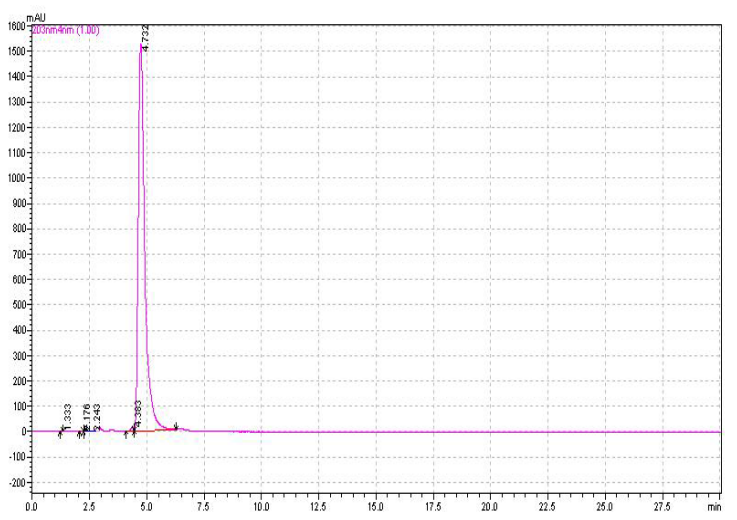

Figure 3: HPLC spectrum of $\mathrm{Cl}-2$.

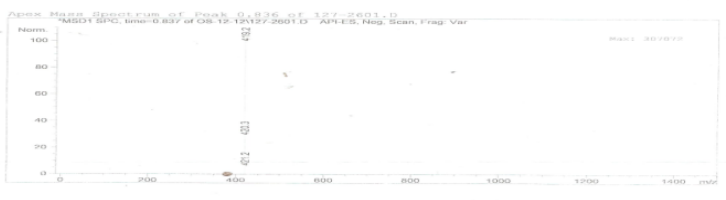

Figure 4: $\mathrm{MS}$ spectrum of $\mathrm{Cl}-2$.
420, the base peak at 419.2. Mass spectrum is depicted in Figure 4.

\section{Characterization of CI-3}

CI-3: Green coloured material. It gave a positive LibermannBurchard test, indicating that it is a steroid. It gave a characteristic green coloured spot on TLC. Compound CI-3 was found to be homogeneous when tested on normal and reverse phase TLC. HPLC analysis also confirmed the homogeneity by giving a single peak at $\lambda_{\max }$ at $211 \mathrm{~nm}$ with Rt 9.6 min (Figure 5).

UV spectrum: UV spectrum of CI-3 was recorded in methanol. It has shown band at $\lambda_{\max } 211 \mathrm{~nm}$. This is the characteristic feature of steroid.

IR $\left(\mathbf{c m}^{-1}\right): 3650(\mathrm{O}-\mathrm{H}), 2977(\mathrm{C}-\mathrm{H}), 1693(\mathrm{C}=\mathrm{O}), 1443(\mathrm{C}-\mathrm{H})$, 1342(C-O), 1196(C-O-C), 867(C-H).

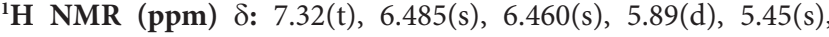
5.428(s), 4.502(s), 4.35(s), 2.57(s), 1.46(d), 1.355(d), 1.188(s), 1.05(d), 0.895(s), 0.856(s), 0.71(s), 0.696(s).

$\mathrm{C}_{13}$ NMR: The peaks at $\delta 161.49(\mathrm{~s}), 161.33(\mathrm{~s}), 157.44(\mathrm{~s}), 157.34(\mathrm{~s})$ 157.19(s), 157.04), 156.89(s), 156.27(s), 141.34(s), 128.10(t), 128.44(s), 27.73(s), 27.47(s).

Mass spectrum: The mass spectrum of compound had a molecular weight $402,(\mathrm{M}+\mathrm{H})^{+}=403,(\mathrm{M}+\mathrm{Na})^{+}=425,(\mathrm{M}+\mathrm{K})^{+}=441,(2 \mathrm{M}+\mathrm{Na})^{+}=827$. Mass spectrum is depicted in Figure 6.

\section{Discussion}

During the present chemical investigation, three compounds were isolated from the methanolic extract of leaves. TLC examination of the methanolic extract of leaves in different solvent systems, both on normal and reverse phases, revealed the presence of light green colour spot and blue colour spot. Hence, this extract was further subjected to column chromatography, using Hexane, and Hexane: Ethylacetate mixtures of different proportions as eluents in gradient elution manner. This chromatography resulted in the isolation of three compounds, which were given codes CI-1, CI-2 and CI-3.

CI-1 is yellow coloured, and it was found to be homogeneous when tested by TLC on reverse and normal phase. It gave green colour in the Libermann-Burchard test and gave purple ring in the Molish test, indicating that it is a steroidal/triterpenoidal glycoside. It had a $\lambda_{\max }$ of $203 \mathrm{~nm}$ and $273 \mathrm{~nm}$. IR spectrum of compound indicated the presence

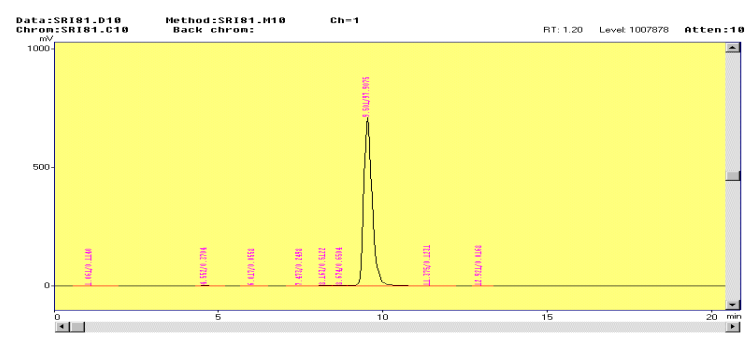

Figure 5: HPLC spectrum of $\mathrm{Cl}-3$.

Figure 6: MS spectrum of $\mathrm{Cl}-3$. 
Citation: Praveena Ch, Swaroopa Rani S, Veeresham C (2013) Phytochemical Investigation of Calophyllum inophyllum Linn. Nat Prod Chem Res 1: 119 doi: 10.4172/ 2329-6836.1000119

Page 4 of 4

of hydroxyl, methylene and carbonyl functional groups. The NMR spectrum of this compound has a peak at $7.25 \mathrm{ppm}$, indicating the presence of aromatic protons, two singlets appearing at 0.805 and 0.898 is assigned to methyl protons; doublet appearing at 1.44 is assigned to the methylene protons.

CI-2 is lemon yellow coloured, it was found to be homogeneous when tested by TLC on reverse and normal phase. It had a $\lambda_{\max }$ at $204 \mathrm{~nm}$. IR spectrum of compound indicated the presence of hydroxyl, carbonyl functional groups. The NMR spectrum of this compound shows a peak at $7.26 \mathrm{ppm}$, indicating the presence of aromatic protons, two singlets appearing at 0.821 and 0.88 were assigned to methyl protons, and peaks ranging at 5.373 to 6.463 were assigned to alkene protons. By comparision of NMR data of compound CI-2 with earlier reports [12] for protons in ${ }^{1} \mathrm{H}$ NMR spectra and functional groups, peaks assignment from $\mathrm{C}_{13} \mathrm{NMR}$ the compound could be a coumarin and it could be calophyllic acid. Molecular weight of compound from Mass spectra was also found to that of calophyllic acid. However, to confirm the structure of CI-2, further spectral analysis has to be carried out.

CI-3 is a green coloured fraction and found to be homogeneous when tested by TLC on reverse and normal phases. It gave red colour in the Libermann-Burchard test and violet ring in Molish test, indicating that it is a steroidal/triterpenoidal glycoside. It had a $\lambda_{\text {ma }} 211 \mathrm{~nm}$. IR spectrum of compound indicated the presence of hydroxyl, methylene and carbonyl functional groups. The NMR spectrum of this compound has peak at $7.32 \mathrm{ppm}$, indicating the presence of aromatic protons. Two doublets appear at 1.46 were assigned to the methylene protons.

Comparision of NMR data of compounds CI-1 and 3 with the earlier reports suggested that they could be coumarins. Further work is in progress to elucidate the structure of this compound.

\section{Conclusion}

Three compounds were isolated and purified from methanolic extract of leaves of Calophyllum inophyllum. Their homogeneity was established by TLC, HPLC analysis. For structure elucidation, UV, IR, ${ }^{1} \mathrm{H}$ NMR, $\mathrm{C}^{13} \mathrm{NMR}$ and Mass spectras were recorded. From preliminary spectral analysis of one dimensional NMR spectra and Mass spectras of the compound CI-2 with earlier reports, the compound could be a coumrin and assumed to be calophyllic acid, as NMR spectra data was correlated. Other two compounds were also suspected to be coumrains from the NMR spectral analysis. The detailed structure elucidation of these compounds is in progress.

\section{References}

1. McKee TC, Covington CD, Fuller RW, Bokesch HR, Young S, et al. (1998) Pyranocoumarins from tropical species of the genus Calophyllum: A chemotaxonomic study of extracts in the National Cancer Institute Collection. J Nat Prod 61: 1252-1256.

2. Kirtikar KR, Basu BD (1987) Indian Medicinal Plants. (2 ${ }^{\text {nd }}$ Edn), International Book Distributors, Dehradun, India.

3. Kawazu K, Ohigashi H, Takahashi N, Mitsui T (1972) Piscicidal constituents of C. inophyllum. Bull Inst Chem Res 50: 160-167.

4. Leu T, Raharivelomanana P, Soulet S, Bianchini JP, Herbette G, et al. (2009) New tricyclic and tetracyclicpyranocoumarins with an unprecedented C-4 substituent. Structure elucidation of tamanolide, tamanlide D, tamanolide $P$ from C. inophyllum French Polynesia. Magnetic Resonance in Chemistry 47 989-993.

5. linuma M, Tosa H, Tanaka T, Yonemori S (1994) Two xanthones from root bark of $C$. inophyllum. Phytochemistry 35: 527-532.

6. Jeboury FSA, Locksley HD (1971) Xanthones in the heartwood of $C$. Inophyllum A geographical survey. Phytochemistry 10: 603-606.

7. Kumar V, Ramachandran S, Sultanbawa MUS (1976) Xanthones and triterpenoids from timber of C. inophyllum. Phytochemistry 15: 2016-2017.

8. Li YZ, Li LZ, Hua HM, Li ZG, Liu MS (2007) Studies on flavonoids from stems and leaves of C. inophyllum. Journal of Chinese Materia Medica 32: 692-694.

9. Laure F, Herbette G, Faure R, Bianchini JP, Raharivelomanana P, et al. (2005) Structures of new secofriedelane and friedelane acids from $C$. inophyllum of French Polynesia. Magnetic Resonance in Chemistry 43: 65-68.

10. Govindachari TR, Vishwanathan N, Pai BR, Ramadas Rao U, Srinivasan M (1967) Triterpenes of C. inophyllum Linn. Tetrahedron Lett 23: 1901-1910.

11. Hang NTM, Chien NQ, Hung NV (2006) Triterpenes from the leaves of Vietnamese plant $C$. inophyllum $\mathrm{L}$. J Chem 44: 115-118.

12. Patil AD, Freyer AJ, Eggleston DS, Haltiwanger RC, Bean MF, et al. (1993) The inophyllums, novel inhibitors of HIV-1 reverse transcriptase isolated from the Malaysian tree, C. inophyllum Linn. J Med Chem36: 4131-38.

13. Spino C, Marco D, Subramaniam S (1998) Anti-HIV coumarins from Calophyllum seed oil. Bioorg Med Chem Lett 8: 3475-3478.

14. Itoigawa M, Ito C, Tan HTW, Kuchide M, Tokuda H, et al. (2001) Cancer chemopreventive agents, 4-phenylcoumarins from $C$. inophyllum. Cancer Lett 169: 15-19.

15. Arora RB, Mathur CN, Seth SD (1962) Calophyllolide, a complex coumarin anticoagulant from C. inophyllum Linn. J Pharm Pharmacol 14: 534-535.

16. Bhalla TN, Saxena RC, Nigam SK, Misra G, Bhargava KP (1980) CalophyllolideA new nonsteroidal anti-inflammatory agent. Ind J Med Res 72: 762-765.

17. Jantan I, Juriyati J, Warif NA (2001) Inhibitory effects of xanthones on platele activating factor on receptor binding in vitro. J Ethnopharmacol 75: 287-290.

18. Wagner $\mathrm{H}$, Bladt S (2002) Plant drug analysis-A TLC atlas. ( $\left.2^{\text {nd }} E d n\right)$, Springer Publications, Berlin, Germany. 